\section{Chorio-retinal thickness measurements in patients with acromegaly}

G Pekel'1 , F Akin², MS Ertürk², S Acer', R Yagci', MC Hıraali ${ }^{1}$ and EN Cetin ${ }^{1}$
${ }^{1}$ Ophthalmology Department, Pamukkale University, Denizli, Turkey

${ }^{2}$ Endocrinology

Department, Pamukkale University, Denizli, Turkey

Correspondence: G Pekel, Ophthalmology Department, Medical School, Pamukkale University, Kınıklı, Denizli 20070, Turkey

Tel: +90 258444 0728-5785

Fax: +90 2582131034

E-mail: gkhanpekel@

yahoo.com

Received: 1 January 2014 Accepted in revised form: 9 August 2014

Published online:

19 September 2014

\begin{abstract}
Purpose To compare choroidal, foveal, and peripapillary retinal thickness between patients with acromegaly and healthy adults. Methods This prospective, cross-sectional, and comparative study included 30 patients with acromegaly (study group) and 30 healthy subjects (control group). The subfoveal choroidal thickness (SFCT), foveal thickness, and peripapillary retinal nerve fibre layer thickness were measured with spectral domain optical coherence tomography.

Results The mean SFCT in the study group and in the control eyes was $374.4 \pm 98.1$ and $308.6 \pm 77.3 \mu \mathrm{m}$, respectively $(P<0.001)$. The mean thinnest foveal thickness value was $233.2 \pm 22.4 \mu \mathrm{m}$ in the acromegaly group and $222.8 \pm 13.9 \mu \mathrm{m}$ in the control group $(P=0.003)$. The mean peripapillary retinal nerve fibre layer thickness did not differ significantly between the groups $(P=0.34)$. Conclusion The SFCT and foveal thickness were significantly higher in patients with acromegaly, whereas peripapillary retinal nerve fibre layer thickness was similar between the groups.

Eye (2014) 28, 1350-1354; doi:10.1038/eye.2014.216; published online 19 September 2014
\end{abstract}

\section{Introduction}

Acromegaly is a rare chronic disease characterised by hypersecretion of growth hormone and insulin-like growth factor 1 (IGF-1) predominantly due to a benign pituitary adenoma. ${ }^{1,2}$ The annual incidence of acromegaly is $\sim 3-4$ cases per million, ${ }^{2,3}$ and it most commonly affects middle-aged adults. ${ }^{4}$ Coarse facial features, large joint arthropathy, skin thickening, sleep apnoea, cardiac hypertrophy, peripheral paresthesias, goiter, insulin resistance, and diabetes mellitus are some of the disorders related with acromegaly. ${ }^{1,5}$

The ocular structures and physiology are also affected by acromegaly. Increased corneal thickness, pigmentary degeneration of the retina, melanocytic tumours of the choroid, enlarged extraocular muscles, proptosis, and total ophthalmoplegia are some of the ocular manifestations of acromegaly. ${ }^{6-11}$ On the other hand, there is a gap in the literature about the impact of acromegaly on the fovea, optic nerve head, and choroid.

In this study, our aim was to evaluate the chorio-retinal thickness in acromegaly patients. We hypothesized that the choroid might be affected owing to increased risk of choroidal tumours or cardiovascular diseases, peripapillary retinal nerve fibre layer (RNFL) might be affected owing to optic nerve compression by enlarged extraocular muscles or sleep apnoea, and fovea might be affected owing to the diabetic features of acromegaly.

\section{Materials and methods}

In this prospective, cross-sectional, and comparative study, a total of 60 participants (30 patients in acromegaly group and 30 healthy adults in control group) were recruited. This study was conducted in accordance with the ethical standards of the Declaration of Helsinki and was approved by the Institutional Ethical Committee.

\section{Study population}

The study group consisted of 30 unrelated acromegaly patients who were treated at the Division of Endocrinology, Pamukkale 
University. The diagnosis of acromegaly was made on the basis of the criteria proposed by Freda ${ }^{12}$ and confirmed by examination of surgically resected tissues. Twenty-seven patients had macroadenoma, while three of them had microadenoma. Twenty-nine patients underwent adenomectomy by transsphenoidal route and one patient refused surgery. All patients had been on treatment with somatostatin analogue lanreotide autogel at the dose of 60-120 mg i.m. every 28 days and octreotide-LAR at the dose of 10-40 mg i.m., also every 28 days. After chronic somatostatin analogue monotherapy, cabergoline was added if IGF-1 levels were not within the age-adjusted normal range. Exclusion criteria were any ocular surgery and any ocular disease other than age-related cataract or mild refractive errors.

\section{Ocular examination techniques}

Both of the eyes of each subject were included, since acromegaly has the potential to affect the eyes nonidentically. ${ }^{10,13-15}$ Visual acuity levels (LogMAR), refractive errors (diopters), intraocular pressure, and retinal vascular caliber measurements were recorded for all the participants. Subfoveal choroidal thickness (SFCT), central foveal thickness, and peripapillary RNFL values were analysed by spectral domain optical coherence tomography (OCT) (Spectralis, Heidelberg Engineering, Heidelberg, Germany). Choroidal thickness was measured from the outer part of the hyper-reflective line corresponding to the retina pigment epithelium to the inner surface of the sclera (Figure 1). For macula analysis, only thinnest foveal thickness was assessed. For peripapillary RNFL analysis, the thicknesses of all the quadrants (superior, inferior, temporal and nasal) were recorded separately. Retinal vessel caliber measurements were taken by using manual caliber tools provided by the Spectralis software on the peripapillary RNFL analysis screen. For retinal vessel caliber analysis, the three largest retinal arterioles and venules passing through an area one-half to one-disc diameter from the optic disc margin were measured (Figure 2).

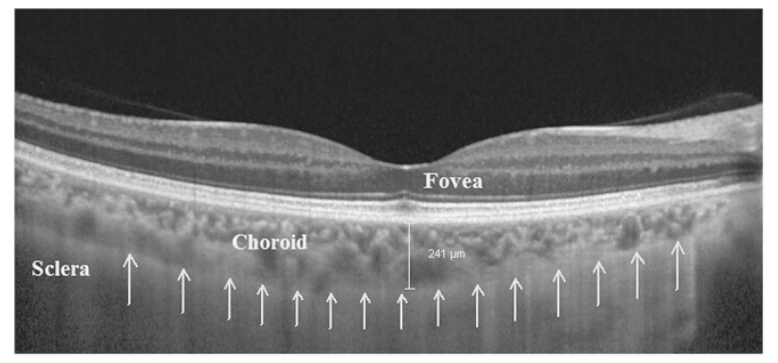

Figure 1 The method for measurement of choroidal thickness. The white arrows indicate the inner surface of the sclera.

\section{Statistical analysis}

For statistical analysis, SPSS 17.0 software for Windows (SPSS Inc., Chicago, IL, USA) was used to analyse outcomes. ' $P$ ' values $<0.05$ were considered to be statistically significant. Independent-samples $t$ test was used for comparison of the studied parameters between the study group and the control group.

\section{Results}

Sixty eyes of thirty acromegaly patients and sixty eyes of thirty healthy volunteers were examined and compared. The mean age of the acromegaly patients was $48.4 \pm 11.9$ years and the mean age of the control group was $49.2 \pm 10.5$ years $(P=0.78)$. There were17 male participants $(57 \%)$ and 13 female participants $(43 \%)$ in both the acromegaly and control groups. Some of the clinical data are presented in Table 1.

The mean time from diagnosis to the start of treatment (surgery or medication) was $50.3 \pm 19.8$ days for the study group. The mean time from the start of treatment to the ocular examinations was $6.9 \pm 6.1$ years. There were no significant correlations between time on treatment and retina-choroidal thickness measurements (Figure 3).

The mean thinnest foveal thickness value was $233.2 \pm 22.4 \mu \mathrm{m}$ in the acromegaly group and $222.8 \pm 13.9 \mu \mathrm{m}$ in the control group $(P=0.003)$. The mean SFCT was $374.4 \pm 98.1 \mu \mathrm{m}$ in the acromegaly group and $308.6 \pm 77.3 \mu \mathrm{m}$ in the control group $(P<0.001)$. The SFCT

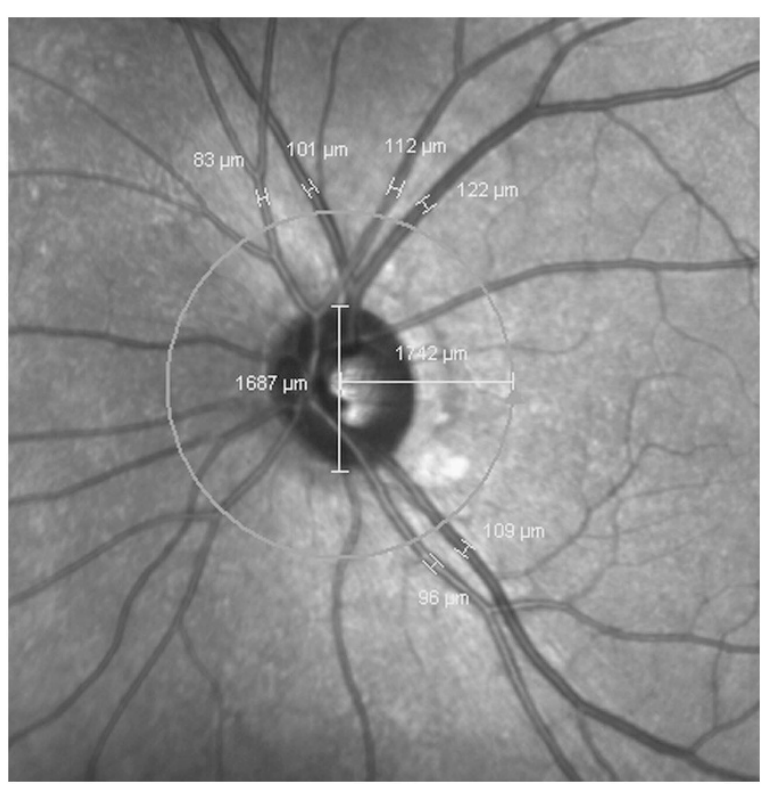

Figure 2 The retinal arteriolar and venular caliber measurement screen. 
values of acromegaly patients were $\sim 21 \%$ thicker than that of the control group.

Mean peripapillary RNFL thickness was $101.1 \pm 14.2 \mu \mathrm{m}$ in the acromegaly group and $103.2 \pm 8.5 \mu \mathrm{m}$ in the control group $(P=0.34)$. The segmental mean peripapillary RNFL thickness (inferior, superior, nasal, and temporal quadrants) measurements are shown in Table 2. All of the segmental RNFL thickness values were similar between the groups.

\section{Discussion}

Growth factors have been demonstrated in the vitreous and retina, in which they aid regulating retinal function. ${ }^{16,17}$ Acromegaly, as a disorder characterised by excess growth factors, might influence the retina, and so the choroid. It was reported that IGF-I might give rise to mild retinal oedema due to increased capillary permeability. ${ }^{18}$ Our results quite support the previous reports and show that acromegaly is associated with increased foveal and choroidal thickness. Additionally, we found that retinal vascular caliber measurements are similar between acromegaly patients and healthy controls.

Researches related to choroidal thickness have been increasing recently owing to the development of

Table 1 Certain clinical characteristics of the patients

\begin{tabular}{lccc}
\hline & Acromegaly & Control & P-value \\
\hline VA (LogMAR) & $0.015 \pm 0.047$ & $0.003 \pm 0.018$ & 0.06 \\
Refraction (SE) & $0.43 \pm 0.95$ & $0.35 \pm 0.63$ & 0.58 \\
IOP (mm Hg) & $14.1 \pm 2.2$ & $14.1 \pm 2.6$ & 0.96 \\
RAC $(\mu \mathrm{m})$ & $91.2 \pm 7.1$ & $91.1 \pm 6.3$ & 0.90 \\
RVC $(\mu \mathrm{m})$ & $120.9 \pm 10.9$ & $119.3 \pm 8.5$ & 0.38 \\
\hline
\end{tabular}

Abbreviations: IOP, intraocular pressure; RAC, retinal arteriolar caliber, RVC, retinal venular caliber; SE, spherical equivalent; VA, visual acuity. enhanced depth OCT. Nevertheless, the determinants of choroidal thickness are not fully understood. In the present study, we found that SFCT values were markedly higher in acromegaly patients. This result might be due to the vascular effects of growth factors, including increased permeability. ${ }^{18}$ Also, there is an association between choroidal tumours and acromegaly, ${ }^{8}$ and this situation might be related to the higher SFCT in acromegaly.

The mammalian retina contains IGF-I and its receptors, in a different organization from other tissues, and have a special distribution within the retina. ${ }^{19}$ Also, treatment with IGF-1 causes mild, generalized, and reversible retinal oedema. ${ }^{18}$ Harvey et $a l^{16}$ reported that growth hormone is present in the human retina and vitreous fluid, and might have a role in some of the ocular disorders. In this study, we found that the fovea was significantly thicker in acromegaly patients. On the other hand, Polat $e a^{20}$ found that central retinal thickness values of acromegaly patients and control subjects were similar. The reason for different outcomes in these studies may be due to performing different measurement techniques for retinal thickness, because we measured the thinnest foveal thickness rather than areal central macular thickness.

Growth factors have become associated with various events of retinal disorders and optic nerve damage. ${ }^{21,22}$ Optic nerve and peripapillary RNFL damage could occur in acromegaly owing to the compression of pituitary adenoma on optic chiasm, ${ }^{4}$ optic nerve compression by enlarged retrobulbar tissues, ${ }^{9}$ increased risk of sleep apnea, ${ }^{5}$ systemic hypertension, ${ }^{5}$ and papilloedema. ${ }^{23}$ Nevertheless, in our study, there was no significant difference between acromegaly and controls, with respect to peripapillary RNFL thickness. Related to this finding, it was reported that acromegaly is not associated with increased intraocular pressure. ${ }^{6}$
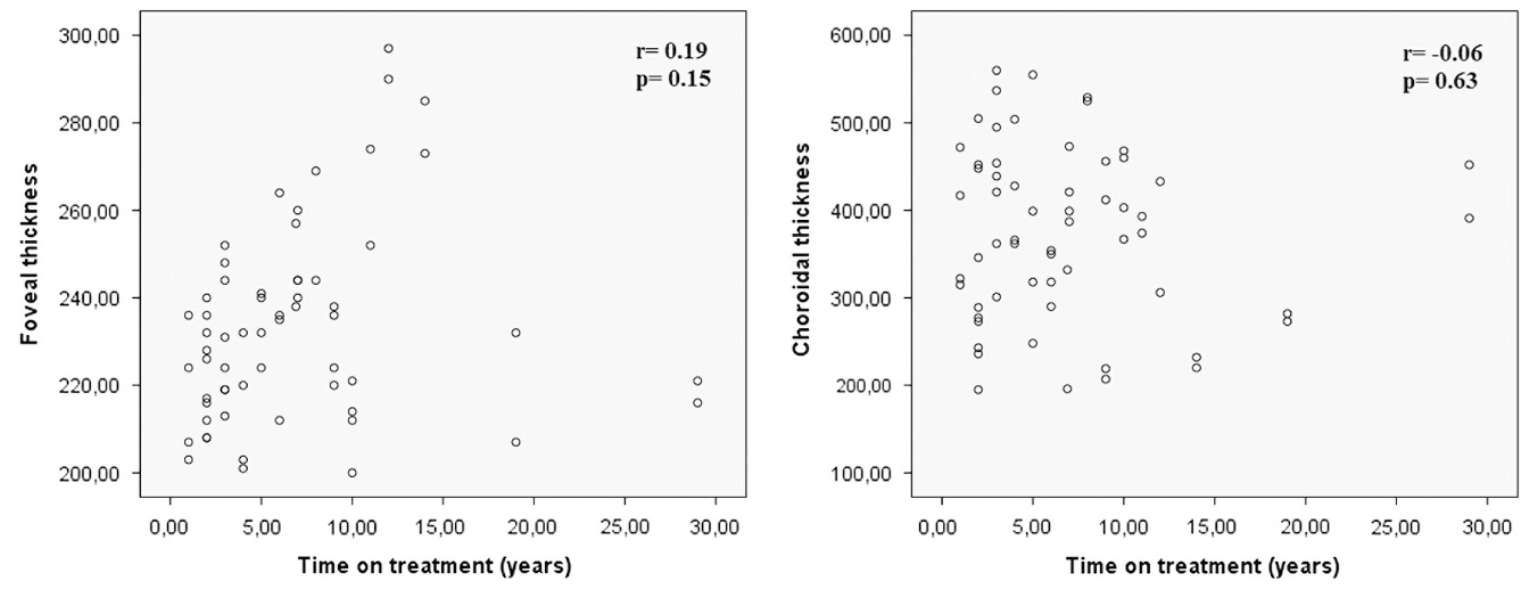

Figure 3 Scatter dot graphics showing the correlations between time on treatment and retina-choroidal thickness measurements. 
Table 2 Segmental peripapillary RNFL thickness (inferior, superior, nasal, and temporal quadrants) measurements

\begin{tabular}{lrrc}
\hline & Acromegaly & Control & P-value \\
\hline Inferior quadrant $(\mu \mathrm{m})$ & $133.6 \pm 22.2$ & $134.2 \pm 14.2$ & 0.86 \\
Superior quadrant $(\mu \mathrm{m})$ & $122.1 \pm 19.8$ & $127.6 \pm 13.2$ & 0.08 \\
Nasal quadrant $(\mu \mathrm{m})$ & $75.7 \pm 18.4$ & $78.4 \pm 12.6$ & 0.37 \\
Temporal quadrant $(\mu \mathrm{m})$ & $73.0 \pm 14.2$ & $72.3 \pm 10.1$ & 0.76 \\
\hline
\end{tabular}

Abbreviation: RNFL, retinal nerve fibre layer.

Our study has several limitations. First, there was a relatively less number of patients, but it should be remembered that acromegaly is a very rare disease. Second, we evaluated the patients during inactive disease status (disease under control), because all of them were taking medications for growth hormone inhibition. Finally, we did not have the opportunity to evaluate vitreal and retinal growth factor levels.

In conclusion, choroidal and foveal thickness values were higher in acromegaly patients, when compared with age- and gender-matched healthy subjects. On the other hand, peripapillary RNFL values were similar between the groups. These results might support the opinion that acromegaly is associated with ocular vascular permeability increase. Further studies including choroidal blood flow measurements, whole macular thickness analysis, fluorescein, and indocyanine green angiography might provide better understanding about the influence of acromegaly, and thus growth hormones, on the retina and choroid.

\section{Summary}

What was known before

- The ocular structures, especially cornea and extraocular muscles, are affected in acromegaly.

\section{What this study adds}

- The choroid and fovea are also affected in acromegaly patients.

- Although, it is likely to find thinner peripapillary RNFL in acromegaly patients, in this study, they did not differ significantly from healthy controls.

- Retinal vascular caliber measurements are similar in acromegaly patients and healthy controls.

\section{Conflict of interest}

The authors declare no conflict of interest.

\section{References}

1 Ben-Shlomo A, Melmed S. Acromegaly. Endocrinol Metab Clin North Am 2008; 37: 101-122.
2 Melmed S. Medical progress: acromegaly. N Engl J Med 2006; 355: 2558-2573.

3 Holdaway IM, Rajasoorya C. Epidemiology of acromegaly. Pituitary 1999; 2: 29-41.

4 Jadresic A, Banks LM, Child DF, Diamant L, Doyle FH, Fraser TR et al. The acromegaly syndrome. Relation between clinical features, growth hormone values and radiological characteristics of the pituitary tumours. Q J Med 1982; 51: 189-204.

5 Ben-Shlomo A, Sheppard MC, Stephens JM, Pulgar S, Melmed S. Clinical, quality of life, and economic value of acromegaly disease control. Pituitary 2011; 14: 284-294.

6 Bramsen T, Klauber A, Bjerre P. Central corneal thickness and intraocular tension in patients with acromegaly. Acta Ophthalmol (Copenh) 1980; 58: 971-974.

7 Cosemans I, Demaerel P, Wets B, De Hauwere B, Spileers W. Retinitis pigmentosa in association with acromegaly: a case report. Doc Ophthalmol 1999; 98: 175-181.

8 Corcuff JB, Ogor C, Kerlan V, Rougier MB, Bercovichi M, Roger P. Ocular naevus and melanoma in acromegaly. Clin Endocrinol (Oxf) 1997; 47: 119-121.

9 Zafar A, Jordan DR. Enlarged extraocular muscles as the presenting feature of acromegaly. Ophthal Plast Reconstr Surg 2004; 20: 334-336.

10 Mehra M, Mohsin M, Sharma P, Dewan T, Taneja A, Kulshreshtha B. Epiphora and proptosis as a presenting complaint in acromegaly: report of two cases with review of literature. Indian J Endocrinol Metab 2013; 17(Suppl 1): S149-S151.

11 Tanriverdi F, Karaca Z, Oner A, Durak AC, Selcuklu A, Unluhizarci $\mathrm{K}$ et al. Complete surgical resolution of bilateral total opthalmoplegia without visual field defect in an acromegalic patient presented with pituitary apoplexy. Endocr J 2007; 54: 681-684.

12 Freda PU. Current concepts in the biochemical assessment of the patient with acromegaly. Growth Horm IGF Res 2003; 13: $171-184$.

13 Nganga HK, Lubanga RP. Pituitary macroadenoma presenting with pituitary apoplexy, acromegaly and secondary diabetes mellitus - a case report. Pan Afr Med J 2013; 15: 39.

14 Heireman S, Delaey C, Claerhout I, Decock CE. Restrictive extraocular myopathy: a presenting feature of acromegaly. Indian J Ophthalmol 2011; 59: 517-519.

15 Tristante G, Cordonnier M, Louryan S, Aguilera C, Unger J. The eye and acromegaly: apropos of a case of ptosis. Bull Soc Belge Ophtalmol 1992; 243: 11-16.

16 Harvey S, Parker E, Macdonald I, Sanders EJ. Growth hormone is present in the human retina and vitreous fluid. Neurosci Lett 2009; 455: 199-202.

17 Harvey S, Baudet ML, Sanders EJ. Growth hormone and cell survival in the neural retina: caspase dependence and independence. Neuroreport 2006; 17: 1715-1718.

18 Hussain MA, Studer K, Messmer EP, Froesch ER. Treatment with insulin-like growth factor I alters capillary permeability in skin and retina. Diabetes 1995; 44: 1209-1212.

19 Ocrant I, Valentino KL, King MG, Wimpy TH, Rosenfeld RG, Baskin DG. Localization and structural characterization of insulin-like growth factor receptors in mammalian retina. Endocrinology 1989; 125: 2407-2413. 
20 Polat SB, Ugurlu N, Ersoy R, Oguz O, Duru N, Cakir B. Evaluation of central corneal and central retinal thicknesses and intraocular pressure in acromegaly patients. Pituitary 2014; 17: 327-332.

21 van Setten G, Brismar K, Algvere P. Elevated intraocular levels of insulin-like growth factor I in a diabetic patient with acromegaly. Orbit 2002; 21: 161-167.
22 Bu SY, Yu GH, Xu GX. Expression of insulin-like growth factor 1 receptor in rat retina following optic nerve injury. Acta Ophthalmol 2013; 91: 427-431.

23 Mueller GL, McKenna TJ, Kelly G, O'Day DM, Hollifield JW, Pidgeon C et al. Papilledema in two patients with acromegaly and intrasellar pituitary tumors. Arch Intern Med 1981; 141: 1491-1495. 